\title{
Size exclusion chromatography for analyses of fibroin in silk: optimization of sampling and separation conditions
}

\author{
Dominika Pawcenis • Monika A. Koperska • \\ Jakub M. Milczarek • Tomasz Lojewski • \\ Joanna Łojewska
}

Received: 2 July 2013 / Accepted: 5 November 2013/Published online: 20 November 2013

(c) The Author(s) 2013. This article is published with open access at Springerlink.com

\begin{abstract}
A direct goal of this paper was to improve the methods of sample preparation and separation for analyses of fibroin polypeptide with the use of size exclusion chromatography (SEC). The motivation for the study arises from our interest in natural polymers included in historic textile and paper artifacts, and is a logical response to the urgent need for developing rationale-based methods for materials conservation. The first step is to develop a reliable analytical tool which would give insight into fibroin structure and its changes caused by both natural and artificial ageing. To investigate the influence of preparation conditions, two sets of artificially aged samples were prepared (with and without $\mathrm{NaCl}$ in sample solution) and measured by the means of SEC with multi angle laser light scattering detector. It was shown that dialysis of fibroin dissolved in $\mathrm{LiBr}$ solution allows removal of the salt which destroys stacks chromatographic columns and prevents reproducible analyses. Salt rich $(\mathrm{NaCl})$ water solutions of fibroin improved the quality of chromatograms.
\end{abstract}

$\begin{array}{ll}\text { Abbreviations } \\ A_{2} & \text { Second virial coefficient in Rayleigh equation } \\ c & \text { Concentration of a solution, } \mathrm{mg} / \mathrm{ml} \\ \lambda & \text { Wavelength of incidental beam (in vacuum), } \mathrm{nm} \\ M_{\mathrm{w}} & \text { Weight average molar mass, derived from } \\ & \text { Rayleigh equation, } \mathrm{g} / \mathrm{mol} \\ n_{0} & \text { Refractive index of a solvent } \\ N_{\mathrm{A}} & \text { Avogadro constant } \\ \mathrm{d} n / \mathrm{d} c & \text { Refractive index increment }\end{array}$

D. Pawcenis $(\bowtie) \cdot$ M. A. Koperska - J. M. Milczarek ·

T. Łojewski · J. Łojewska

Chemistry Faculty, Jagiellonian University, Ingardena 3, 30-060 Kraków, Poland

e-mail: pawcenis@chemia.uj.edu.pl
$P(\theta) \quad$ Form factor in Rayleigh equation

$R(\theta)$ Excess Rayleigh ratio, the difference between Rayleigh ratio for a solution and a pure solvent

$g \quad$ Branching ratio

$R_{\text {lin }}^{2} \quad$ Mean square radius of linear sample

$R_{\mathrm{br}}^{2} \quad$ Mean square radius of branched sample

\section{Introduction}

Silk fibres have been used for centuries in the textile industry due to their characteristic strength and beautiful lustre. Nowadays, thanks to its biocompatibility and biodegradability silk is finding numerous new applications in biotechnology [1] (i.e. wound dressing [2], tissue engineering [3], targeted drug delivery [4]).

The most direct information regarding the condition of the historical silk textiles or silk-based modern products could be obtained from measurements of the molecular weight distribution of the fibroin polymer-a major component of a silk fibre. Silk analysis by size exclusion chromatography (SEC) is, however, challenging. The difficulties arise mainly from a sample preparation method or more precisely the choice of a solvent, which in some cases could lead to degradation [5] and/or aggregation of fibroin [6]. Presented work focuses on the optimization of the sample preparation method and separation conditions to obtain reproducible and reliable results of molar mass of Bombyx mori silk fibroin.

Since there are no standards of fibroin of a given average molar mass, a thermal degradation can be applied to obtain a series of silk samples differing in mass. Thermal degradation effects can be classified into two groups: one involves purely physical (structural) changes in the fibre, whereas the other involves chemical changes. Thermal 
treatment of silk fibroin leads to the changes in its amino acids composition and to the scissions in protein chains, which results in the changes in molar mass distribution. It is worth noting here that non-crystalline areas are more affected by heat then the crystalline ones [7].

\section{State of the art in SEC analysis of silk fibroin}

Traditionally, the extent of degradation of silk fabrics has been measured by the loss of its mechanical endurance $[8$, 9], colour [10], crystalline structure by x-ray diffraction $[11,12]$, and viscosity $[13,14]$. However, today these have been replaced by more advanced analytical methods involving:

- solid-state ${ }^{13} \mathrm{C}$ NMR for amino acid sequences $[15,16]$,

- Sodium dodecyl sulphate polyacrylamide gel electrophoresis (SDS-PAGE) to measure molecular weight of silk subunits [17],

- SEC to determine molecular weight distribution [10, 14].

The latter method, size exclusion chromatography, is most commonly applied for the analysis of polymers, but fibroin problems associated with its dissolution and the stability of the obtained solution substantially limit its use.

Silk originated fibroin solutions can be obtained by two methods. In the first approach, the liquid silk secreted in the silk gland is directly dispersed in water. The other way is to use chemical agents to dissolve previously degummed silk fibroin and this technique is most often used for sample preparation for SEC analysis of silk [10, 14, 18-20]. It must be highlighted that degumming applies only to fibroin coming from extruded silk of cocoons. The degumming process is utilized to remove sericin coating from silk fibre. Dissolution of silk fibres can be processed in aqueous solutions of chaotropic salts [21] like: LiSCN [10, 14,], $\mathrm{LiBr}$ [6, 20, 22-25]; mixed solvents like: $\mathrm{CaCl}_{2} / \mathrm{EtOH} / \mathrm{H}_{2} \mathrm{O}$ [26] or $\mathrm{Ca}\left(\mathrm{NO}_{3}\right)_{2} / \mathrm{MeOH}$ [27] and in non-aqueous solvents, e.g. hexafluoroisopropanol [18], $\mathrm{N}$-methylmorpholine $\mathrm{N}$ oxide [28] and $N$-methylmorpholine $N$-oxide with addition of protic solvents like DMSO [29].

Amongst the solutions of salts surveyed by Sashina et al. [21] the most popular were concentrated solutions of lithium salts such as for example LiSCN and LiBr. Aqueous solutions of lithium thiocyanate as well as lithium bromide are very good solvents for fibroin, which is assigned to the nucleophilicity of anion attacking hydroxy, amide and amino groups. Since, solvency of lithium cations is of the greatest efficiency, lithium salt solutions are the most common solvents, used for dissolution of silk fibres. The conclusion is, however, that dependently on the applied measurement technique, removal of lithium bromide should be considered to improve the separation conditions. For various applications, dialysis appears as a method that allows easy removal of a salt from a fibroin solution. It is worth mentioning that lithium bromide in water is used as a solvent for viscosity measurements in accordance to "Silk Viscosity Test Using Lithium Bromide" standard [24].

Except $\mathrm{LiBr}$, lithium thiocyanate is often used as aqueous solvent. Thiocyanate anion has slightly higher nucleophilic properties comparing to bromide anion [21]. Kim and Wyeth [10] and Tse and Dupont [14] presented relatively broad studies on silk fibroin dissolved in saturated LiSCN. Calculation of molecular weights required in both cases, subtraction of LiSCN peaks from SEC chromatograms, which could lead to systematic errors, especially for degraded silk of low molar mass. In addition, applicability of this solvent for routine SEC analyses is questionable, since typically used columns (i.e. silica-based Biosep from Phenomenex) require salt concentrations to be kept below $1 \mathrm{M}$ and its $\mathrm{pH}$ below 7.5. Saturated LiSCN solutions $(>10 \mathrm{M})$ of high $\mathrm{pH}$ could drastically shorten service lifetime of columns. Another obstacle is that precipitation from concentrated salt solution may cause clogging inside pipes in the chromatographic system, particularly the columns, which generally makes it difficult to conduct SEC analyses with saturated solutions.

Mixed solvent systems such as $\mathrm{CaCl}_{2} / \mathrm{EtOH} / \mathrm{H}_{2} \mathrm{O}$ or $\mathrm{Ca}\left(\mathrm{NO}_{3}\right)_{2} / \mathrm{MeOH}$ seem to be superior to the single salt solutions mentioned above due to low costs and good solvency, which lead to higher concentrations of silk fibroin. Unfortunately, in these systems the loss of molecular weight of fibroin molecules is observed [20].

A simple method of sample preparation via direct dissolution of freshly spun spider silk in mobile phase of hexafluoroisopropanol (HFIP) was also described in the literature [18]. HFIP is transparent to UV light and has low refractive index (RI) which makes this solvent convenient for analyses with UV or RI detection. HFIP is also commonly used in biochemistry to monomerize $\beta$-sheet protein aggregates, thus this particularly raises its applicability in molecular weight determination which would be undisturbed by formation of aggregates.

$\mathrm{N}$-methylmorpholine $\mathrm{N}$-oxide (MMNO) was proved to be efficient solvent of silk fibroin [28], also in combination with aprotic solvents like DMSO [29]. Dissolution by MMNO occurs in the crystal regions of a protein, which are more homogeneous and contain mainly glycine and alanine amino acids. Freddi et al. [28] investigated degrading influence of MMNO on silk fibroin. Observed decrease in measured intrinsic viscosity values indicated depolymerisation of fibroin chains. Moreover, MMNO has oxidative properties, which sometimes might be an eliminating factor. For these reasons, MMNO cannot be used for investigation of silk fibroin degradation. 
According to our knowledge, there were only a few approaches to silk textile analyses by SEC that consider silk fibroin degradation. It can be due to difficulties in sample preparation, proper choice of dissolving agent and its influence on separation process. In previously described studies [10, 14] of fibroin dissolution in saturated LiSCN, no further separation of dissolved fibroin and LiSCN was used which leads to the problems described above. In light of literature findings there is a need for improvement in the sample preparation method, avoiding degradation and aggregation of fibroin and that would allow analyses of fibroin fractions of low molecular weight from highly degraded silk and at the same time would not be detrimental to the SEC set-up.

In this paper, we focus on optimization of the procedure of sample preparation to obtain accurate and reproducible analyses of the molecular weights distribution of silk fibroin, also for highly degraded samples. From available options: a silk fibroin solvent and an agent for further dialysis, aqueous solution of $9.3 \mathrm{M}$ lithium bromide, were chosen.

\section{Experimental}

\subsection{Samples}

\subsubsection{Accelerated ageing of silk fibroin samples}

Commercial degummed Chinese B. mori silk (35 g/ $\mathrm{m}^{-2}$ ) was used in all experiments. Prior to accelerated ageing, the samples were cut into pieces (c.a. $0.07 \mathrm{~g}$ ), dried for $15 \mathrm{~min}$ at $110{ }^{\circ} \mathrm{C}$, sealed in glass vials (acting as ageing vessels) and aged at $150{ }^{\circ} \mathrm{C}$ for 1 and $336 \mathrm{~h}$ (14 days). Moisture content in ageing vessels was adjusted to obtain contrasting conditions-dry, semihumid and humid, with $\mathrm{RH}$ values equal, correspondingly, to $0 \% \mathrm{RH}, 30 \% \mathrm{RH}$ and $70 \% \mathrm{RH}$ as calculated for $293 \mathrm{~K}$ and $1,013 \mathrm{hPa}$.

\subsection{Size exclusion chromatography}

\subsubsection{Sample preparation}

Approximately $0.07 \mathrm{~g}$ of silk textile was dissolved in 9.3 M lithium bromide, as proposed by Swiss Standard for viscosity test of silk textiles [24]. Solutions were thermostated in water bath for $3 \mathrm{~h}$ at $60{ }^{\circ} \mathrm{C}$ until samples completely dissolved. Dissolution was followed by dialysis in a cellulose membrane tube (molecular weight cut-off $12.8 \mathrm{kDa}$, Sigma) against pure water (Millipore) for 3 days. The dialysis solution was exchanged every $12 \mathrm{~h}$ to remove LiBr. A parallel set of fibroin samples was prepared with $\mathrm{NaCl}$ addition. The solutions were prepared by mixing one volume of $0.4 \mathrm{M} \mathrm{NaCl}$ solution with three volumes of each sample to obtain silk fibroin in $0.1 \mathrm{M} \mathrm{NaCl}$. Prior to SEC analyses, samples were filtered using RC syringe filters $0.45 \mu \mathrm{m}$ (Sartorius). For the reason that the silk fibroin solutions were transparent and had no visible insoluble residues we omitted the centrifugation step. However, it is known from the literature [30] that in the case of the silk fibroin solutions in pure water, SEC analysis has to be performed soon after dialysis due to gelation of silk fibroin after prolonged storage. Regarding $\mathrm{NaCl}$ influence on silk, according to our experience the samples treated with $\mathrm{NaCl}$ solution can be stored for much longer time with no gelation than the samples that have not been treated with $\mathrm{NaCl}$. Samples used in this experiment remained liquid after 4 months of storage in a fridge. Nevertheless, due to microbial growth, it is not recommended to run SEC analysis of samples stored for long period [31], as microorganisms present in both sample and mobile phase may lead to increasing noise in the MALLS detector.

The protein concentration for $\mathrm{d} n / \mathrm{d} c$ determination was measured using Bradford standard assay procedure [32].

\subsubsection{Analyses}

The SEC system consisted of the following items: Waters 1515 isocratic pump, Waters 717 +auto sampler, a column oven, a multi angle laser light scattering detector Dawn Heleos (Wyatt Technology) and a differential refractive index detector Optilab T-rEX (Wyatt Technology), acting as a concentration sensitive detector. Both detectors, MALLS and RI, worked at the same wavelength $(658 \mathrm{~nm})$. In the literature $[33,34]$ such a SEC configuration for protein analyses is well described.

Chromatographic separation was performed on silicabased column BioSep SEC S-4000 from Phenomenex (packed $5 \mu \mathrm{m}, 300 \times 4.6 \mathrm{~mm}$ ), maintained at $30^{\circ} \mathrm{C}$ (the same temperature as in RI detector), a downstream guard column was used (Phenomenex, $300 \times 4.6 \mathrm{~mm}$ ). Water (HPLC grade, Carl Roth) was used as a mobile phase, with a flow rate of $0.30 \mathrm{ml} / \mathrm{min}$. Silk fibroin samples were injected in volumes ranging from 50 to $100 \mu \mathrm{l}$. Each sample was analysed six times-three injections from two solutions prepared from separate pieces of fabric aged under the same conditions.

The specific refractive index increment of fibroin was determined in batch mode using differential refractive index detector Optilab T-rEX and calculated in Astra 6.0.2 software (Wyatt Technology). 


\section{Data processing/calculations}

\subsection{Chromatographic results}

The determination of absolute values of molecular weights using size exclusion chromatography with MALLS detection is based on Rayleigh equation:

$\frac{k \cdot c}{R(\theta, c)}=\frac{1}{M_{\mathrm{w}} P(\theta)}+2 A_{2} c$

where $k$ is a combined constant including the refractive index increment $\mathrm{d} n / \mathrm{d} c$ :

$k=\left(2 \pi^{2} n_{0}^{2}\left(\frac{\mathrm{d} n}{\mathrm{~d} c}\right)^{2}\right)\left(\frac{1+\cos ^{2} \alpha}{N_{\mathrm{A}} \lambda_{0}^{4}}\right)$

There are several parameters that have to be known to apply Rayleigh equation: fibroin concentration $c$, its specific refractive index increment $\mathrm{d} n / \mathrm{d} c$ and second virial coefficient $A_{2}$.

Concentration values came from differential refractive index detector (concentration sensitive). Specific refractive index value was obtained from four batch measurements of five different concentration of fibroin in water, ranging from 0.035 to $1.764 \mathrm{mg} / \mathrm{ml}$ and was equal to $0.171 \pm 0.007 \mathrm{ml} / \mathrm{g}$. In general, most proteins have a $\mathrm{d} n /$ $\mathrm{d} c$ value close to $0.170 \mathrm{ml} / \mathrm{g}$ independently of amino acid composition [35].

Second virial coefficient $A_{2}$ has not been successfully determined yet. On-line approach to $A_{2}$ calculation was performed. A phrase "on-line determination" may indeed seem a little odd, but it has been used in the literature before [36]. Thus, the on-line determination of $A_{2}$ means that it has been derived from the experiments performed by injecting a series of known concentrations of the fibroin in an ascending order to a SEC column. If the mass recovery from such experiments is $100 \%$ than this approach can be used to construct Zimm's plot. However, the values obtained in that procedure were ambiguous, probably due to co-elution of fibroin protein adsorbed on column during previous runs. This phenomenon is quite common for SEC of protein, especially when pure water as mobile phase is used. Co-elution was not observed during a standard SEC analysis probably due to long enough intervals between sample injections. However, we would like to admit that during the on-line $A_{2}$ determination, eluting peaks (in the interval c.a. $15 \mathrm{~min}$ ) were slightly noisy and somewhat distorted. To avoid molar masses errors affected by the lack of second virial coefficient, very small concentrations of protein were injected to the column (order of $10^{-3} \mathrm{mg}$ / $\mathrm{ml})$.

Weight average molar mass from Rayleigh equation was calculated with the use of Debye's model, which is

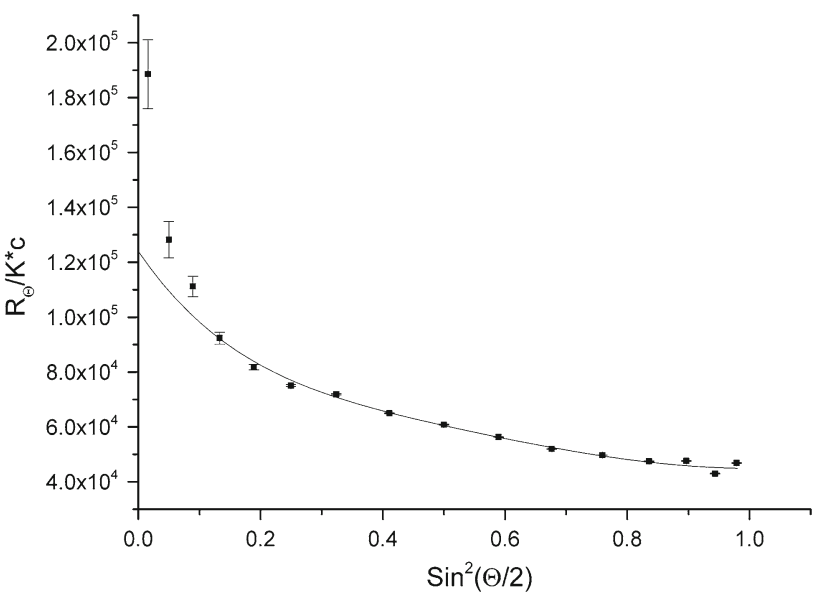

Fig. 1 Debye's plot of angular dependence of scattered light for dialysed and separated silk fibroin (reference sample)

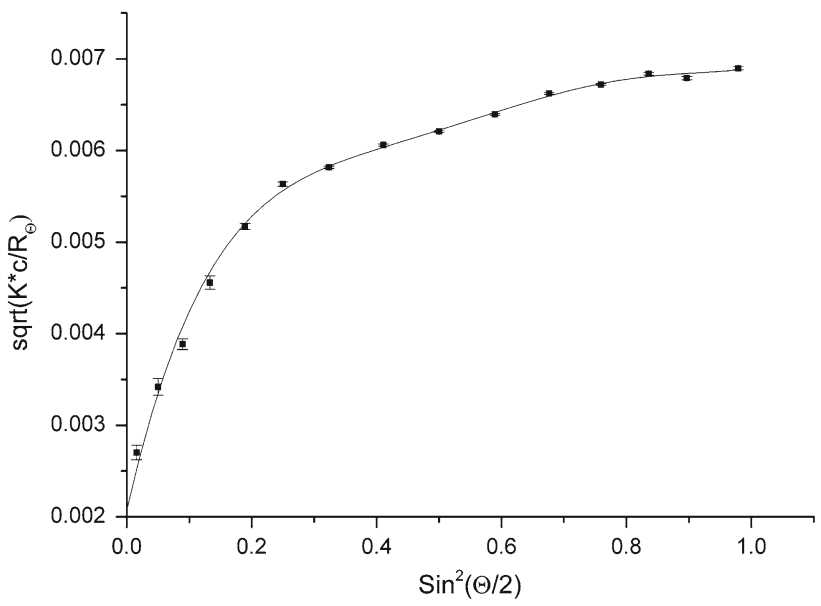

Fig. 2 Berry's plot of angular dependence of scattered light for dialysed and separated silk fibroin (reference sample)

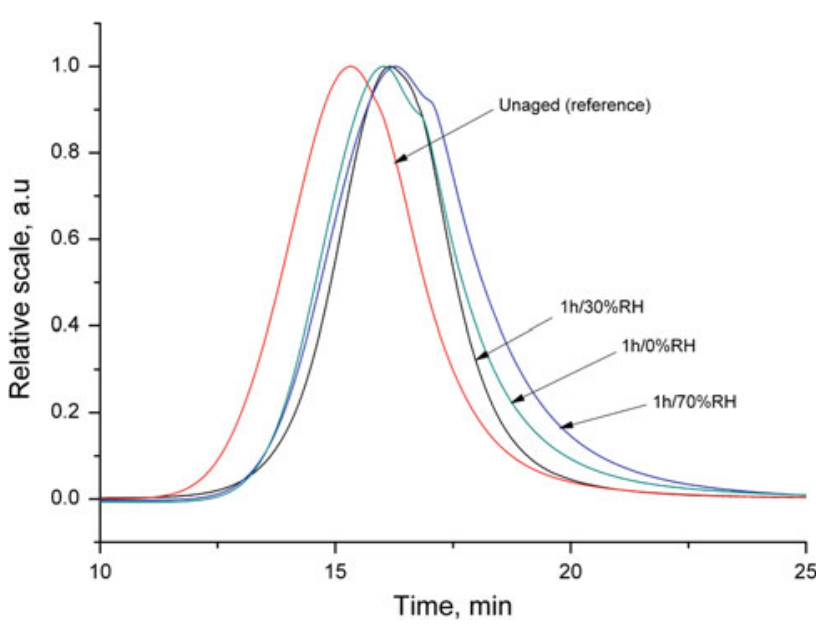

Fig. 3 Elution profile (light scattering detector) for silk samples aged for $1 \mathrm{~h}$, with $\mathrm{NaCl}$ included in the solvent 
recommended for large molecules [37]. A plot of $R_{\theta} /$ $k \times c$ versus $\sin ^{2}(\theta / 2)$ was constructed. The plot was fitted by a polynomial to obtain the intercept at zero angle and the slope at zero angle as well. In this study, the fit was of the fifth order, as there was highly pronounced curvature on Debye's plot, which is assigned to find the presence of aggregates [37-39]. This curvature was presented independently of the fitting model used (comparison presented on Berry's model, which is suitable for large molecules, too).

Calibration of MALLS detector requires determination of detector constant which is a proportionality factor

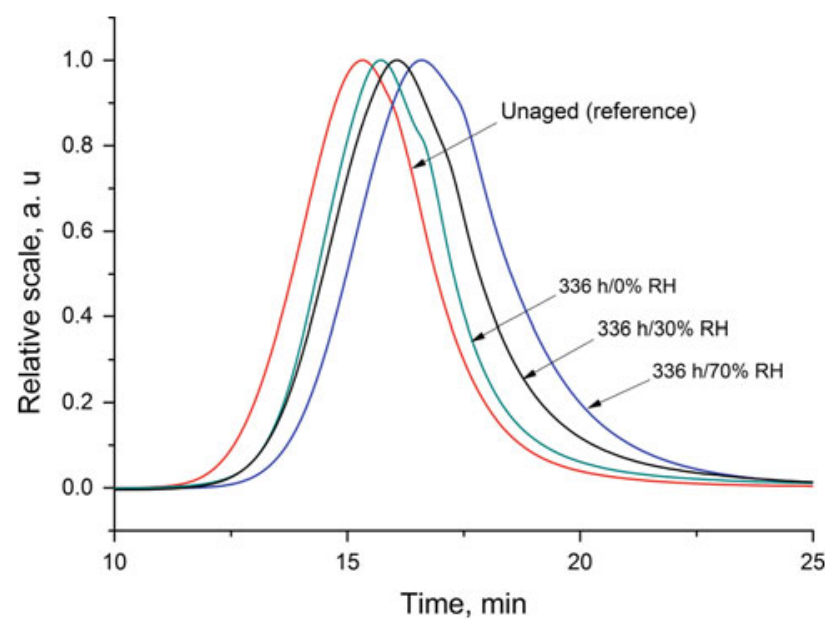

Fig. 4 Elution profile (light scattering detector) for silk samples aged for $336 \mathrm{~h}$, with $\mathrm{NaCl}$ included in the solvent between the detector signal and the Rayleigh coefficient $R(\theta)$ for one photodiode ( 11 th, on $\left.90^{\circ}\right)$. The detector constant determination was performed with toluene (HPLC purity) and was found to be $1.5511 \times 10^{-4} 1 / \mathrm{V}$. Further procedure includes normalization of other 17 photodiodes, which was done using a Pullulan standard (40 kDa, Fluka). Inter-detector delay was determined with the value of $0.9009 \mathrm{ml}$ with the use of Pullulan (125 kDa, Fluka).

\section{Results}

\subsection{Fitting model}

As mentioned in section "Chromatographic results", Debye's fitting method was applied for calculations of weight average molar mass. For all samples (referenceunaged silk, and aged samples), the curvature of Debye's plot was observed. Fitting method referring to Berry's formalism was also checked, but the difference in both results was negligible. The shapes of both plots from both methods showed curvatures (Figs. 1,2).

\subsection{Molecular weight distribution of silk fibroin}

Weight average molar mass was calculated from equation:

$M_{\mathrm{w}}=\frac{\sum H_{\mathrm{i}} M_{\mathrm{i}}}{\sum H_{\mathrm{i}}}$

We decided to use weight average molar masses, because a difference between $M_{\mathrm{w}}$ and $M_{\mathrm{v}}$ is very small
Fig. 5 Weight average molar masses of silk fibroin before and after thermoageing, obtained by separation without $\mathrm{NaCl}$ addition

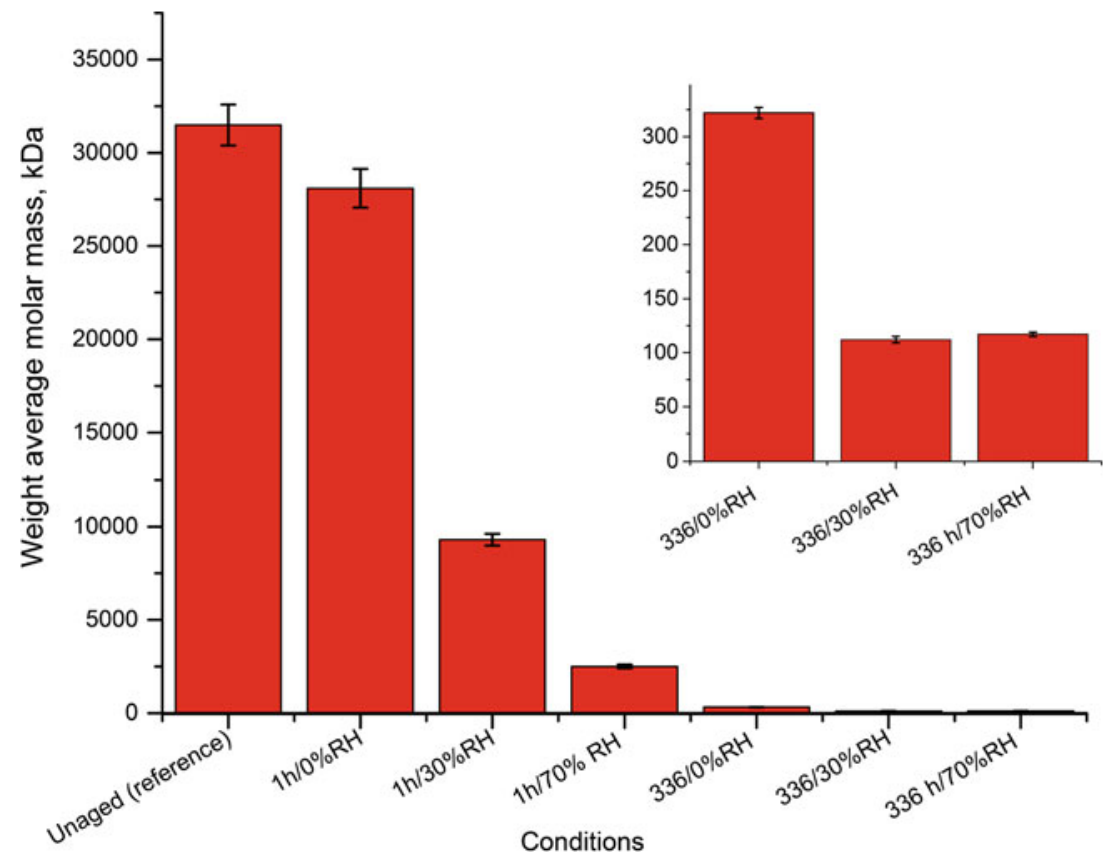


Fig. 6 Weight average molar masses of silk fibroin before and after thermoageing, obtained by separation with $\mathrm{NaCl}$ addition

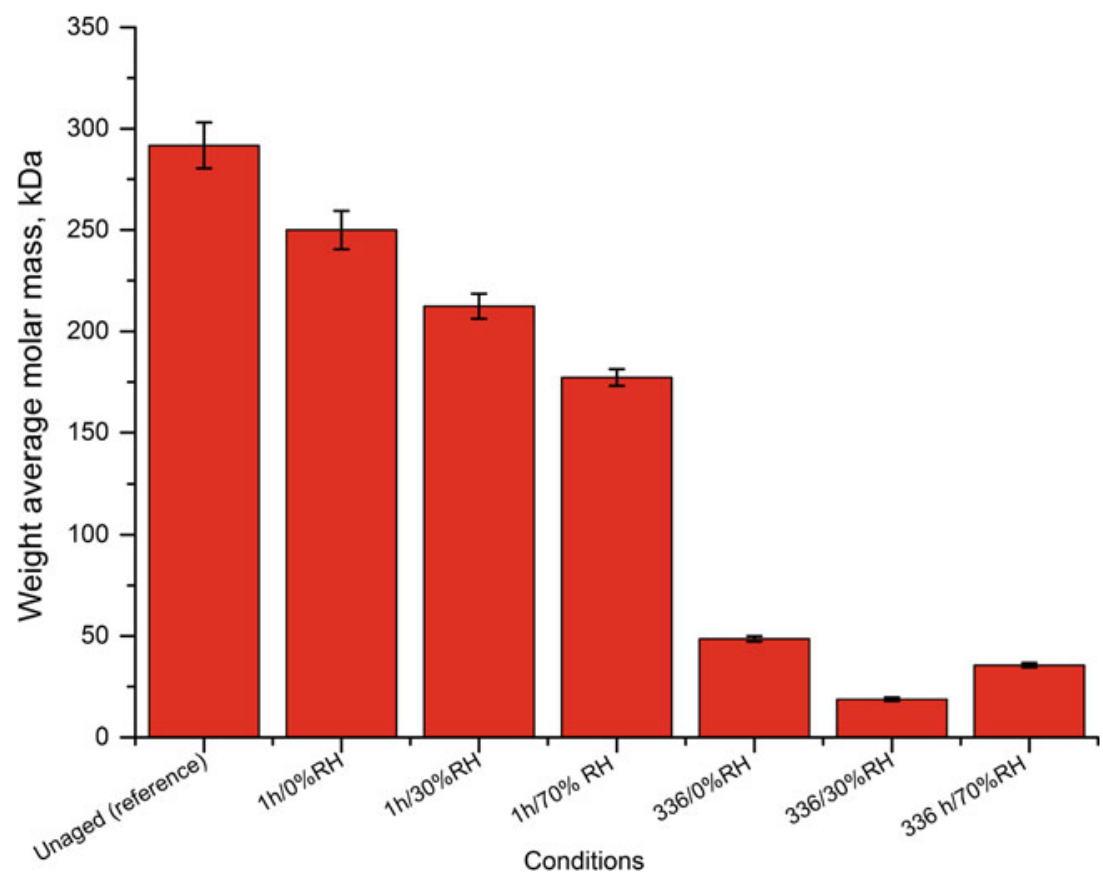

(correlation of SEC and viscosity results for studied samples is in progress).

The elution profiles from the light scattering and refractive index detectors for the silk samples indicated a shoulder on the peak (Figs. 3, 4), coming from the occurrence of light and heavy chains in a fibroin fibre.

The observed peak can also be attributed to aggregation of fibroin molecules, taking into account the use of pure water as a mobile phase. To assess the influence of water as a mobile phase on the fibroin conformation the dependence of molar mass on root mean square radius, called a conformation plot analysis, has been obtained. Slopes derived from this relation provide the information on the conformation of a macromolecule in a given solvent. For the silk fibroin in pure water, the slopes values equal to $0.44 \pm 0.08$ indicate random coil conformation of a protein [40]. However, we are aware of the fact that more accurate determination requires the use of viscometric detector in SEC configuration which is not available in our laboratory.

Molecular weights obtained for experiments in which $\mathrm{NaCl}$ was not present may confirm aggregation phenomenon (Fig. 5). The values calculated for unaged silk textile are greater by up to 100 times in comparison with the samples where $0.1 \mathrm{M} \mathrm{NaCl}$ was added (Fig. 6). This result highlights the impact of salt presence on aggregation and separation efficiency of fibroin and supports the statement presented by Hagn et al. [41], where significant changes were observed in elution volumes of silk (specifically: $\mathrm{N}$-terminal domain of spider dragline silk) when $\mathrm{NaCl}$ was used as an additive to the mobile phase. In addition, using dissolution in $\mathrm{LiBr}$ and dialysis of the silk solutions to
Table 1 Decrease in weight average molar masses with increasing ageing time compared for a set of samples with no $\mathrm{NaCl}$ and with $\mathrm{NaCl}$

\begin{tabular}{lrrlc}
\hline Sample & $\begin{array}{l}M_{\mathrm{w}}[\mathrm{kDa}] \\
\text { (in pure } \\
\text { water) }\end{array}$ & $\sigma[\mathrm{kDa}]$ & $\begin{array}{l}M_{\mathrm{w}}[\mathrm{kDa}] \\
(0.1 \mathrm{M} \mathrm{NaCl} \\
\text { added) }\end{array}$ & $\sigma[\mathrm{kDa}]$ \\
\hline Reference (unaged) & 31,490 & 1,100 & 292 & 11 \\
$1 \mathrm{~h} / 0 \% \mathrm{RH}$ & 28,095 & 1,040 & 250 & 10 \\
$1 \mathrm{~h} / 30 \% \mathrm{RH}$ & 9,296 & 317 & 212 & 6 \\
$1 \mathrm{~h} 70 \% \mathrm{RH}$ & 2,506 & 98 & 177 & 4 \\
$336 \mathrm{~h} / 0 \% \mathrm{RH}$ & 322 & 5 & 49 & 1 \\
$336 \mathrm{~h} / 30 \% \mathrm{RH}$ & 112 & 3 & 19 & 1 \\
$336 \mathrm{~h} / 70 \% \mathrm{RH}$ & 117 & 2 & 36 & 1 \\
\hline
\end{tabular}

prepare the samples overcomes the limitations of previous methods and ensures the chromatograms are not disrupted by LiSCN peaks.

The value of weight average molar mass of reference silk sample is close to the value determined with SDSPAGE electrophoresis method $(350 \pm 25 \mathrm{kDa})$ [17]. Our experiments provided the value of $292 \pm 11 \mathrm{kDa}$ for unaged silk textile (Table 1). Thus, it supports the argument that dissolution in $\mathrm{LiBr}$ followed by dialysis does not cause serious depolymerisation of fibroin chain [17, 20].

It has been observed that with longer ageing time and increased relative humidity, molecular weight decreases, which is consistent with the results obtained for silk textiles artificially aged in experiments performed under other conditions than those used by authors [10, 14]. However, the measured decrease in $M_{\mathrm{w}}$ values is not linear and the greatest change is observed in first hour of ageing. 
Fig. 7 Molecular weight distribution of all analysed samples (reference and thermoaged)

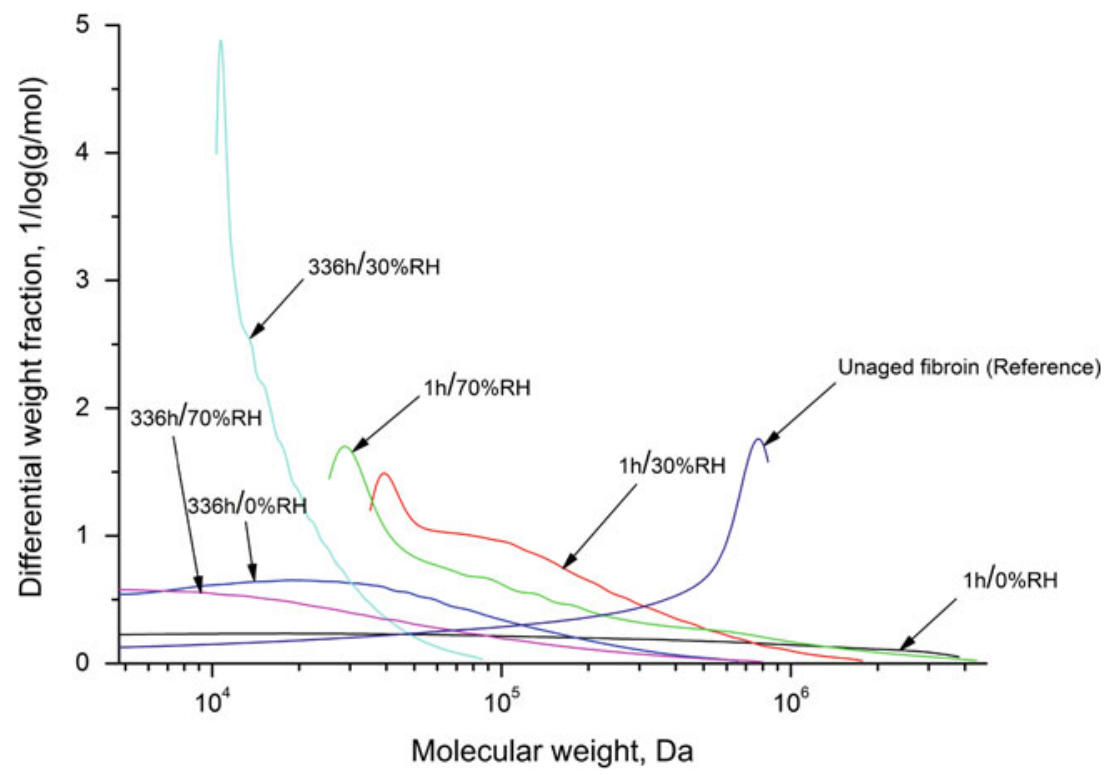

Molecular weight distribution curves (Fig. 7) demonstrate broad range with higher low $M_{\mathrm{w}}$ contributions for the $336 \mathrm{~h}$ aged samples. This may suggest a need for decreasing ageing temperature, as rapid and uncontrolled degradation of polypeptide chain can occur under these conditions. Moreover, each curve has bimodal distribution, which can be attributed both to disordered depolymerisation and simultaneous depolymerisation of light and heavy chains in fibroin.

For samples without the addition of $\mathrm{NaCl}$ (reference and aged for longer period of time in $70 \% \mathrm{RH}$ ) branching ratio $(g)$, calculated from Zimm-Stockmeyer's Eq. (4), was lower than unity. No branching model fitted with a good accuracy, which suggests aggregation of fibroin molecules. This phenomenon is in agreement with the hypothesis stated in [6], where pronounced aggregation of silk fibroin molecules in pure water was observed. The Debye's plot curvature mentioned above confirms this hypothesis.

$g=\frac{R_{\mathrm{br}}^{2}}{R_{\mathrm{lin}}^{2}}$

where $R_{\mathrm{br}}^{2}$ and $R_{\mathrm{lin}}^{2}$ are root mean square of a branched and linear molecule, respectively. The parameter $g$ is also called the contraction factor. This ratio is equal to unity for linear polymers and decreases with increasing extent of branching [37].

The obtained branching ratio of a value lower than unity in this case indicates more protein aggregation rather than cross-linking, as only thermal degradation was simulated. Branching ratios for unaged fibroin and aged for $336 \mathrm{~h}$ were equal to $0.44 \pm 0.08$ and $0.83 \pm 0.06$, respectively.
Cross-linking of fibroin via radical mechanism is possible under photo ageing in ultraviolet light [42].

\section{Conclusions}

Advantages of silk fibroin preparation involving removal of $\mathrm{LiBr}$ by dialysis followed by diluting with $\mathrm{NaCl}$ solution to obtain fibroin in $0.1 \mathrm{M} \mathrm{NaCl}$ are as follows:

(i) No use of an agent that affects a column due to high value of $\mathrm{pH}$ ( $\mathrm{pH}$ of $\mathrm{LiBr}$ exceeds range of $\mathrm{pH}$ for silica-based columns), which provides longer lifetime of columns,

(ii) Elimination of protein molecules aggregation, which is likely to occur in $\mathrm{LiBr}$ and pure water,

(iii) Good method to follow depolymerisation in fibroin, and consequently evaluating condition of historic silk textiles.

Notwithstanding the advantages presented above, a question whether the use of water as a mobile phase and addition of $\mathrm{NaCl}$ only to a sample is sufficient is still valid. Pure water used as a mobile phase is very convenient, as there is no need for system flushing, preparation of buffers and greater viscosity of mobile phase. However, the presence of salts in concentration up to $0.5 \mathrm{M}$ is maintained to improve separation on a column and to prevent interactions between proteins in solution and proteins with column packing [43].

Acknowledgments The research was performed within SPB 811/NCOST/2010/0 from National Science Centre. Materials and chemicals were purchased thanks to financial support from National Science Centre project 2011/01/N/ST4/03604. 
Open Access This article is distributed under the terms of the Creative Commons Attribution License which permits any use, distribution, and reproduction in any medium, provided the original author(s) and the source are credited.

\section{References}

1. C. Vepari, D.L. Kaplan, Prog. Polym. Sci. 32, 991 (2007)

2. H. Teramoto, T. Kameda, Y. Tamada, Biosci. Biotech. Biochem. 72, 3189 (2008)

3. Y. Wang, H.J. Kim, G. Vunjak-Novakovic, D.L. Kaplan, Biomaterials 27, 6064 (2006)

4. E. Wenk, H.P. Merkle, L. Meinel, J. Control. Release 150, 128 (2011)

5. K. Matsumoto, H. Uejima, T. Iwasaki, Y. Sano, H. Sumino, J. Appl. Polym. Sci. 60, 503 (1996)

6. K.S. Hossain, N. Nemoto, J. Magoshi, Langmuir 15, 4114 (1999)

7. Y. Yanagi, Y. Kondo, K. Hirabayashi, Test. Res. J. 70, 871 (2000)

8. X. Zhang, I.V. Berghe, P. Wyeth, J. Cult. Herit. 12, 408 (2001)

9. P. Garside, P. Wyeth, X. Zhang, E. Preserv. Sci. 7, 126 (2010)

10. J. Kim, P. Wyeth, E. Preserv. Sci. 6, 60 (2009)

11. A.C. Hermes, R.J. Davies, S. Greiff, H. Kutzke, S. Lahlil, P. Wyeth, C. Riekel, Biomacromolecules 7, 777 (2006)

12. P. Garside, P. Wyeth, Appl. Phys. A 89, 871 (2007)

13. X. Zhang, S. Yuan, Chin. J. Chem. 28, 656 (2010)

14. S. Tse, A.L. Dupont, Historic textiles, papers and polymers in museums, in Measuring silk deterioration by high performance size exclusion chromatography, viscometry and electrophoresis, ed. by J.M. Cardamon, M.T. Baker (American Chemical Society, Washington, 2001)

15. T. Asakura, J. Yao, T. Yamane, K.E. Umemura, A.S. Ulrich, J. Am. Chem. Soc. 124, 8794 (2002)

16. R. Chujo, A. Shimaoka, K. Nagaoka, A. Kurata, M. Inoue, Polymer 37, 3693 (1996)

17. H. Yamada, H. Nakao, Y. Takasu, K. Tsubouchi, Mater. Sci. Eng. C 14, 41 (2001)

18. C. Jackson, J.P. O’Brien, Macromolecules 28, 5975 (1995)

19. W.A. Gaines, M.G. Sehorn, W.R. Marcotte, J. Biol. Chem. 285, 40745 (2010)

20. H.J. Cho, C.S. Ki, H. Oh, K.H. Lee, I.C. Um, Int. J. Biol. Macromol. 51, 336 (2012)
21. E.S. Sashina, A.M. Bochek, N.P. Novoselov, D.A. Kirichenko, Russ. J. Appl. Chem. 79, 869 (2006)

22. K.S. Hossain, E. Ohyama, A. Ochi, J. Magoshi, N. Nemoto, J. Phys. Chem. B 107, 8066 (2003)

23. K. Sah, K. Pramanik, Int. J. Environ. Sci. Develop. 1, 404 (2010)

24. Swiss Standards Association, Silk viscosity test using lithium bromide, textile Rundscheu, 80, 19 (1964)

25. B. Zuo, L. Liu, F. Zhang, J. Appl. Polym. Sci. 113, 2160 (2009)

26. Y. Joo-Hong, L. Kwang-Gill, L. Yong-Wo, K. Sun Yeou, Eur. Polym. J. 39, 1195 (2003)

27. A.B. Mathur, A. Tonelli, T. Tathke, S. Hudson, Biopolymers 42, 61 (1997)

28. G. Freddi, G. Pessina, M. Tsukada, Int. J. Biol. Macromol. 24, 251 (1999)

29. E.S. Sashina, N.P. Novoselov, K. Heinemann, Russ. J. Appl. Chem. 76, 128 (2003)

30. A. Matsumoto, J. Chen, A.L. Collette, U.-J. Kim, G.H. Altman, P. Cebe, D.L. Kaplan, J. Phys. Chem. B 110, 21630 (2006)

31. R. Scherrers, Noise problems in SEC-MALS, Wyatt Technology Europe GmbH 2009, support documents Wyatt Technology, http://wyatt.eu/index.php?id=support-documents-hardware. Accessed 3 Sep 2013

32. M.M. Bradford, Anal. Biochem. 72, 248 (1976)

33. A. Oliva, M. Llabrés, J.B. Farina, J. Pharm. Biomed. Anal. 25 , $833(2001)$

34. K.S. Hossain, A. Ochi, E. Ooyama, J. Magoshi, N. Nemoto, Biomacromolecules 4, 350 (2003)

35. J. Wen, T. Arakawa, J.S. Philo, Anal. Biochem. 240, 155 (1996)

36. S. Girod, P. Baldet-Dupy, H. Maillols, J.M. Devoisselle, J. Chromatogr. A 943, 147 (2002)

37. S. Podzimek, Light scattering, size exclusion chromatography and asymmetric flow field flow fractionation (John Wiley\&Sons, Inc, Chicester, 2011)

38. P. Kratochvil, in Light scattering from polymer solutions, ed. by M.B. Huglin (Academic, New York, 1972)

39. A.J. Hyde, C. Wippler, J. Polym. Sci. 58, 1083 (1962)

40. W.H. Fissell, C.L. Hofmann, R. Smith, N.H. Chen, Am. J. Physiol. Ren. Physiol. 298, 205 (2010)

41. F. Hagn, C. Thamm, T. Scheibel, H. Kessler, Angew. Chem. Int. Ed. 50, 310 (2011)

42. S. Baltova, V. Vassileva, Polym. Degrad. Stab. 60, 53 (1998)

43. T. Arakawa, D. Ejima, T. Li, J.S. Philo, J. Pharm. Sci. 99, 1674 (2010) 